\title{
APPLICATION OF HIGH-PERFORMANCE THIN-LAYER CHROMATOGRAPHIC METHOD FOR THE SIMULTANEOUS DETERMINATION OF LAMIVUDINE AND TENOFOVIR DISOPROXIL FUMARATE IN PHARMACEUTICAL DOSAGE FORM
}

\author{
P. CHANDRA, A. S. RATHORE, L. SATHIYANARAYANAN, K. R. MAHADIK*
}

Department of Pharmaceutical Chemistry, Poona College of Pharmacy, Bharati Vidyapeeth Deemed University, Erandwane, Pune 411038, Maharashtra, India (Received: December 6, 2010 - Accepted: April 26, 2011)

\begin{abstract}
A simple, precise and accurate high performance thin layer chromatographic method has been developed for the simultaneous determination of lamivudine (LAM) and tenofovir disoproxil fumarate (TDF) in pharmaceutical dosage form. The separation was carried out on Merck HPTLC aluminum plates of silica gel $60 \mathrm{~F}_{254},(20 \times 10 \mathrm{~cm})$ with $250 \mu \mathrm{m}$ thickness using chloroform: methanol: toluene $(8: 2: 2, \mathrm{v} / \mathrm{v} / \mathrm{v})$ as mobile phase. HPTLC separation of the two drugs followed by densitometric measurement was carried out in the absorbance mode at $265 \mathrm{~nm}$. The drugs were satisfactorily resolved with $R_{\mathrm{f}}$ values of $0.27 \pm 0.01$ and $0.51 \pm 0.01$ for LAM and TDF, respectively. The linear regression analysis data for the calibration plots showed good linear relationship with $\mathrm{r}^{2}=0.9999$ and 0.9996 for LAM and TDF, respectively in the concentration range of $60-210 \mathrm{ng} \mathrm{spot}^{-1}$ for each drug. The method was validated for precision, robustness, specificity and accuracy. The limit of detection and quantitation were 20 and $40 \mathrm{ng} \mathrm{spot}^{-1}$, respectively for LAM and 30 and $60 \mathrm{ng} \mathrm{spot}^{-1}$, respectively for TDF. The proposed developed HPTLC method can be applied for identification and quantitative determination of LAM and TDF in bulk drug and pharmaceutical dosage form.
\end{abstract}

Keywords: lamivudine; tenofovir disoproxil fumarate; HPTLC; validation.

\section{INTRODUCTION}

Lamivudine (LAM); [4-amino-1-[(2R,5S)-2-(hydroxymethyl)-1,3oxathiolan-5-yl]-1,2-dihydro pyrimidin-2-one] is a cytosine analog reverse transcriptase inhibitor that is active against HIV-1, HIV-2, and HBV. The molecule has two chiral centers and is manufactured as the pure $2 R$, cis(-)enantiomer ${ }^{1}$ (Figure 1). LAM enters cells by passive diffusion, where it is converted to the monophosphate by deoxycytidine kinase, and undergoes further phosphorylation by deoxycytidine monophosphate kinase and nucleoside diphosphate kinase to yield lamivudine 5'-triphosphate, which is the active anabolite ${ }^{2}$. The intracellular triphosphate acts as a competitive inhibitor of reverse transcriptase and is incorporated into HIV DNA to cause chain termination ${ }^{3}$.

Tenofovir (TDF); is a derivative of adenosine 5'-monophosphate and chemically it is 9-[(R)-2-[[(isopropoxcarbonyl)-oxy]methoxy]phosphiny $]$ methoxy]propyl]adeninefumarate ${ }^{4}$ (Figure 2). It is a nucleotide reverse transcriptase inhibitor used in combination with other antiretrovirals for the treatment of HIV infection ${ }^{5}$. Because the parent compound had very poor oral bioavailability, TDF is available only as the disoproxil fumarate prodrug, which has improved oral absorption and cellular penetration substantially. Like LAM and emtricitabine, TDF is active against HIV-1, HIV-2, and HBV 6,7.<smiles></smiles>

Figure 1. Structure of LAM

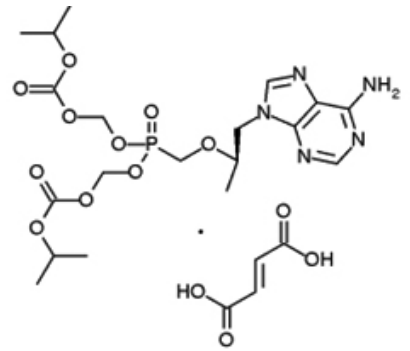

Figure 2. Structure of TDF
Literature survey reveals that LAM is estimated individually and in combination with other drugs by UV spectrophotometry ${ }^{8,9,10,15,16}$, RP-HPLC ${ }^{11}$, $12,13,14,15,16$, plasma RP-HPLC ${ }^{17}, 18,19$. Forced decomposition behavior of LAM using LC-MS/TOF ${ }^{20}$, estimation in human peripheral blood mononuclear cells by LC-MS/MS ${ }^{21}$, HPTLC ${ }^{16,22,23}$ and stability-indicating HPTLC assay method ${ }^{24}$ have been reported.

Similarly for TDF, RP-HPLC ${ }^{25}$, RP-HPLC in human plasma ${ }^{26}$, plasma LC/ $\mathrm{MS} / \mathrm{MS}^{27,28}$ and HPTLC $^{29}$ methods have been reported.

From the above literature survey it is very clear that no method has been reported for simultaneous determination of LAM and TDF. Nowadays, HPTLC is becoming a routine analytical technique due to its advantages. The major advantage of HPTLC is that several samples can be run simultaneously using a small quantity of mobile phase unlike HPLC, thus lowering analysis time and cost per analysis. So, the present study is designed for the development and validation of simple HPTLC method for the simultaneous determination of LAM and TDF in bulk drug and pharmaceutical dosage form. The proposed method is validated as per ICH guidelines ${ }^{30}$.

\section{EXPERIMENTAL}

\section{Materials}

Working standards of pharmaceutical grade LAM $(99.70 \%, \mathrm{w} / \mathrm{w})$ and TDF ( $99.86 \%$, w/w) were obtained as gift samples from Emcure Pharmaceuticals Ltd., Pune, Maharastra, India. Fixed dose combination tablet (TAVIN-L Emcure Pharmaceuticals Ltd.) containing $300 \mathrm{mg}$ LAM and $300 \mathrm{mg}$ TDF was purchased from Kalyani Medicals, Pune, Maharastra, India. All chemicals and reagents were of analytical grade and purchased from Merck Chemicals, Mumbai, Maharastra, India.

Selection of analytical wavelength

Stock solutions of drugs were prepared in methanol separately. UV spectrum of $10 \mu \mathrm{g} \mathrm{mL}^{-1}$ of each individual drug was taken. Further, in situ HPTLC spectral overlain of LAM and TDF was taken.

Instrumentation and chromatographic conditions

The HPTLC plates were prewashed with methanol and activated at 110 ${ }^{\circ} \mathrm{C}$ for $5 \mathrm{~min}$ prior to chromatography. The samples were spotted in the form of bands $6 \mathrm{~mm}$ width with a Camag 100 microlitre sample syringe (Hamilton, Bonaduz, Switzerland) on silica gel precoated HPTLC aluminum plate 60 $\mathrm{F}_{254},[(20 \times 10 \mathrm{~cm})$ with $250 \mu \mathrm{m}$ thickness; E. Merck, Darmstadt, Germany, supplied by Anchrom Technologists, Mumbai] using a Camag Linomat IV applicator (Switzerland). A constant application rate of $0.1 \mu \mathrm{Ls}^{-1}$ was used and the space between two bands was $6 \mathrm{~mm}$. Linear ascending development was carried out in $20 \mathrm{~cm} \times 10 \mathrm{~cm}$ twin trough glass chamber (Camag, Muttenz, Switzerland) saturated with the mobile phase. The mobile phase was consisted of chloroform: methanol: toluene $(8: 2: 2, \mathrm{v} / \mathrm{v} / \mathrm{v})$ and $24 \mathrm{~mL}$ were used per chromatography run. The optimized chamber saturation time for mobile phase was $30 \mathrm{~min}$ using saturation pads at room temperature $\left(25^{\circ} \mathrm{C} \pm 2\right)$. The length of chromatogram run was $8 \mathrm{~cm}$. Densitometric scanning was performed using 
a Camag TLC scanner III in the reflectance-absorbance mode and operated by CATS software (V 3.15, Camag). The slit dimension was kept at $5 \mathrm{~mm} \times 0.45$ $\mathrm{mm}$ and the scanning speed was $10 \mathrm{~mm} \mathrm{~s}^{-1}$. The source of radiation used was a deuterium lamp emitting a continuous UV spectrum between 190 and $400 \mathrm{~nm}$. All determinations were performed at ambient temperature with a detection wavelength of $265 \mathrm{~nm}$. Concentrations of the compound chromatographed were determined from the intensity of the diffused light. Evaluation was by peak areas with linear regression.

\section{Standard solutions and calibration graphs}

Mixed stock standard solution containing $3.00 \mathrm{mg} \mathrm{mL}^{-1}$ each of LAM and TDF was prepared in methanol by dissolving $150 \mathrm{mg}$ each of LAM and TDF in $50 \mathrm{ml}$ methanol. This was further diluted with methanol to obtain working standard solutions in a concentration range of 60-210 ng spot ${ }^{-1}$ for LAM and 60$210 \mathrm{ng} \mathrm{spot}^{-1}$ for TDF. Each concentration was applied six times on the HPTLC plate. The plate was then developed using the previously described mobile phase. The peak areas were plotted against the corresponding concentrations to obtain the calibration graphs. Linear calibration curves were generated using least-squares linear-regression analysis.

\section{Sample preparation}

To determine the content of LAM and TDF simultaneously in pharmaceutical dosage form TAVIN-L (label claim: $300 \mathrm{mg}$ LAM and 300 mg TDF per tablet, B. No. 01A10009, Emcure Pharmaceuticals Ltd.). Twenty tablets were weighed and finely powdered. An accurate weight of the powder equivalent to $300 \mathrm{mg}$ of LAM and $300 \mathrm{mg}$ of TDF was weighed. This was then transferred into a $100 \mathrm{~mL}$ volumetric flask containing $50 \mathrm{~mL}$ methanol, sonicated for $30 \mathrm{~min}$ and diluted to $100 \mathrm{~mL}$ with methanol. $1 \mathrm{~mL}$ of the above solution was transferred to $25 \mathrm{~mL}$ volumetric flask and diluted to volume with methanol. This solution was filtered through a $0.45 \mu \mathrm{m}$ nylon syringe filter. The concentration achieved after the above dilution was $120 \mathrm{ng} \mu \mathrm{L}^{-1}$ of LAM and TDF each. $1 \mu \mathrm{L}$ volume was spotted for six times to achieve a final concentration of $120 \mathrm{ng} \mathrm{spot}^{-1}$ for LAM and TDF respectively. The plate was developed in the previously described chromatographic conditions. The peak area of the spots were measured at $265 \mathrm{~nm}$ for LAM and TDF, respectively and the concentrations in the samples were determined using multilevel calibration developed on the same plate under the same conditions using linear regression equation.

\section{Method validation}

The optimized HPTLC method was validated with respect to the following Parameters. The validation was performed as per the ICH guidelines ${ }^{30}$.

\section{Precision}

Precision of the method was determined with the standard and the real sample. The precision of the method was verified by repeatability (intraday) and intermediate precision studies. Repeatability studies were performed by analysis of three different concentrations of working standard of $60,150,210$ ng spot ${ }^{-1}$ for LAM and 60, 150, $210 \mathrm{ng} \mathrm{spot}^{-1}$ for TDF. Method repeatability was achieved by repeating the same procedure six times on the same day for intraday precision. The intermediate (interday) precision of the method was checked by performing same procedure on different days under the same experimental conditions. The repeatability of sample application and measurement of peak area for active compound were expressed in terms of relative standard deviation (\% R.S.D.) and standard error (S.E.).

An amount of the sample powder equivalent to the label claim of LAM and TDF was accurately weighed and assayed. System repeatability was determined by six replicate applications and six times measurement of a sample solution at a concentration of $120 \mathrm{ng} \mathrm{spot}^{-1}$.

\section{Robustness}

The robustness was studied by evaluating the efect of small but deliberate variations in the chromatographic conditions. Following the introduction of small changes in the mobile phase composition $( \pm 0.1 \mathrm{~mL}$ for each component), the efect on the results was examined. Mobile phases having different compositions, e.g. chloroform: methanol: toluene $(8.1: 2: 2, \mathrm{v} / \mathrm{v} / \mathrm{v}),(8: 2.1: 2$, $\mathrm{v} / \mathrm{v} / \mathrm{v}),(8: 2: 2.1, \mathrm{v} / \mathrm{v} / \mathrm{v})$ were tried and chromatograms were run. The amount of mobile phase was varied over the range of $\pm 5 \%$. The time from spotting to chromatography and from chromatography to scanning was varied by $+10 \mathrm{~min}$. The robustness of the method was determined at three different concentration levels of $60,150,210 \mathrm{ng} \mathrm{spot}^{-1}$.

\section{Limit of detection and limit of quantitation}

The detection limit of an individual analytical procedure is the lowest amount of analyte in a sample that can be detected but not necessarily quantitated as an exact value. The quantitation limit of an individual analytical procedure is the lowest amount of analyte in a sample that can be quantitatively determined with suitable precision and accuracy. In order to estimate the limit of detection (LOD) and limit of quantitation (LOQ), the signal to noise ratio
$(\mathrm{S} / \mathrm{N})$ of 3 and 10 was determined for six replicate determinations. Specificity

The ability of an analytical method to unequivocally assess the analyte in the presence of other components. The specificity of the method was determined by analyzing standard drug and test samples. The spot for LAM and TDF in the samples was confirmed by comparing the $R_{\mathrm{f}}$ and spectrum of the spot to that of a standard. The peak purity of LAM and TDF was determined by comparing the spectrum at three diferent regions of the spot i.e. peak start $(\mathrm{S})$, peak apex (M) and peak end (E).

\section{Accuracy}

Accuracy of the proposed method was carried out by applying the method to pharmaceutical dosage form (LAM and TDF combination tablets) to which known amounts of LAM and TDF standard powder corresponding to 50 , 100 and $150 \%$ of label claim had been added (standard addition method). The absolute recovery was calculated by comparing the peak areas obtained from standard solution of LAM and TDF with the peak areas of samples of different concentration. Six determinations at each level of concentration were performed and the results obtained were compared with expected results.

\section{RESULTS AND DISCUSSION}

\section{Selection of analytical wavelength}

LAM and TDF showed maximum absorbance at $272 \mathrm{~nm}$ and $260 \mathrm{~nm}$, respectively. Isoabsorptive point was found at $265 \mathrm{~nm}$ (Figure 3). Further, in situ HPTLC spectral overlain of LAM and TDF was taken. Isoabsorptive point was found at $265 \mathrm{~nm}$ and was selected as scanning wavelength (Figure 4).

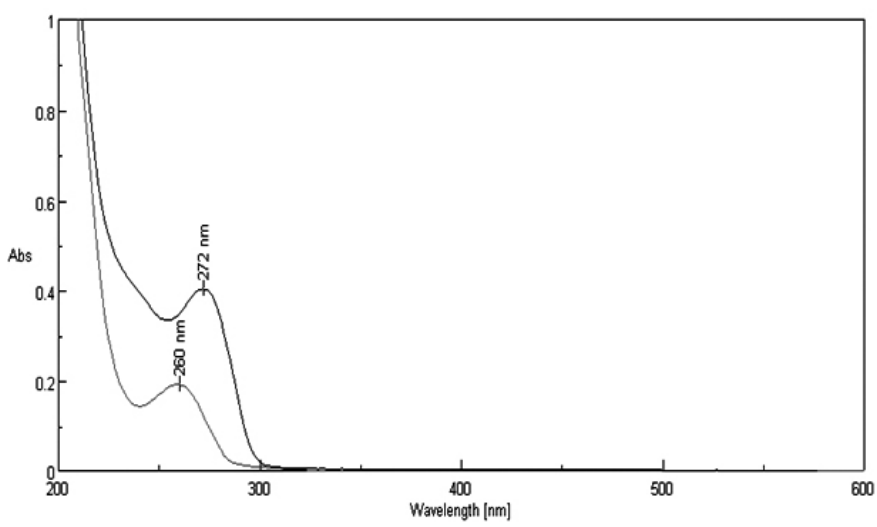

Figure 3. UV spectrum overlay of LAM and TDF.

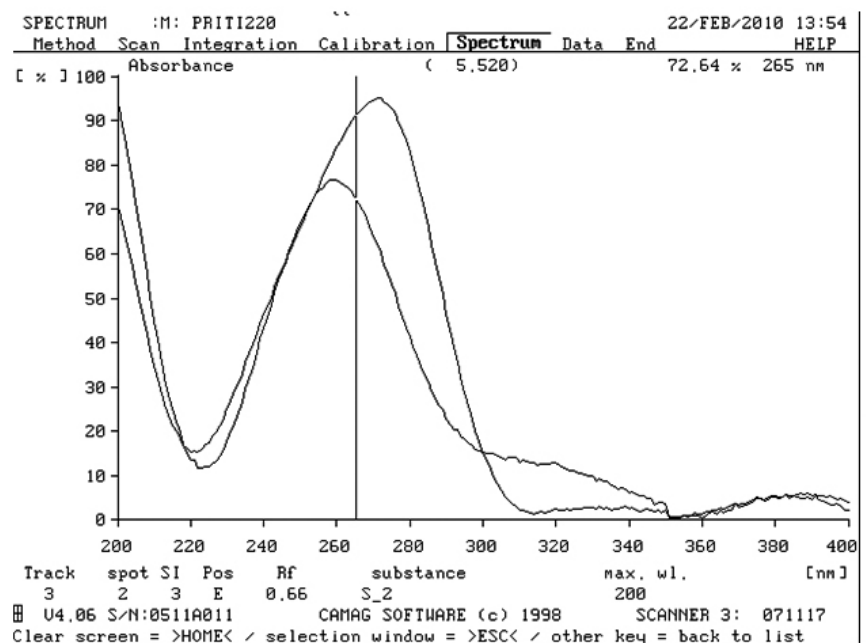

Figure 4. In situ HPTLC spectral overlain of LAM and TDF.

\section{Optimization of procedures}

The experimental conditions for HPTLC such as wavelength of detection and mobile phase composition were optimized to provide accurate, precise 
and reproducible results for the simultaneous determination of LAM and TDF A scanning wavelength of $265 \mathrm{~nm}$ was obtained as a common wavelength concluded from UV spectrum overlay and in situ HPTLC spectral overlay of LAM and TDF. The mixed standard stock solution containing $1.00 \mathrm{mg} \mathrm{mL}^{-1}$ of LAM and $1.00 \mathrm{mg} \mathrm{mL}^{-1}$ of TDF were spotted onto Merck HPTLC silica gel precoated aluminum plate $60 \mathrm{~F}_{254},(20 \times 10 \mathrm{~cm})$ with $250 \mu \mathrm{m}$ thickness and run in different solvent systems. Initially, toluene, ethyl acetate and methanol were tried in different ratio. Resolution achieved was not satisfactory. Finally, chloroform, methanol \& toluene were tried in different ratio. A good resolution and sharp peaks were obtained with minimum tailing by using an optimum mobile phase consisted of chloroform: methanol: toluene (8:2:2, v/v/v). LAM and TDF were satisfactorily resolved with $R_{\mathrm{f}}$ values at $0.27 \pm 0.01$ and $0.51 \pm$ 0.01 , respectively.

Linearity

Linear relationships were observed by plotting drug concentration against peak areas for each compound. LAM and TDF showed linear response in the concentration range of $60-210 \mathrm{ng}$ spot $^{-1}$, respectively. The corresponding linear regression equation was $\mathrm{y}=16.14 \mathrm{x}+170.9$ and $\mathrm{y}=8.694 \mathrm{x}+341.4$ with square of correlation coefcient $\left(\mathrm{r}^{2}\right)$ of 0.9999 and 0.9996 for LAM and TDF, respectively. Residual analysis was performed to ascertain linearity (Figure 5). No significant difference was observed in the slopes of standard curves (Table 1).
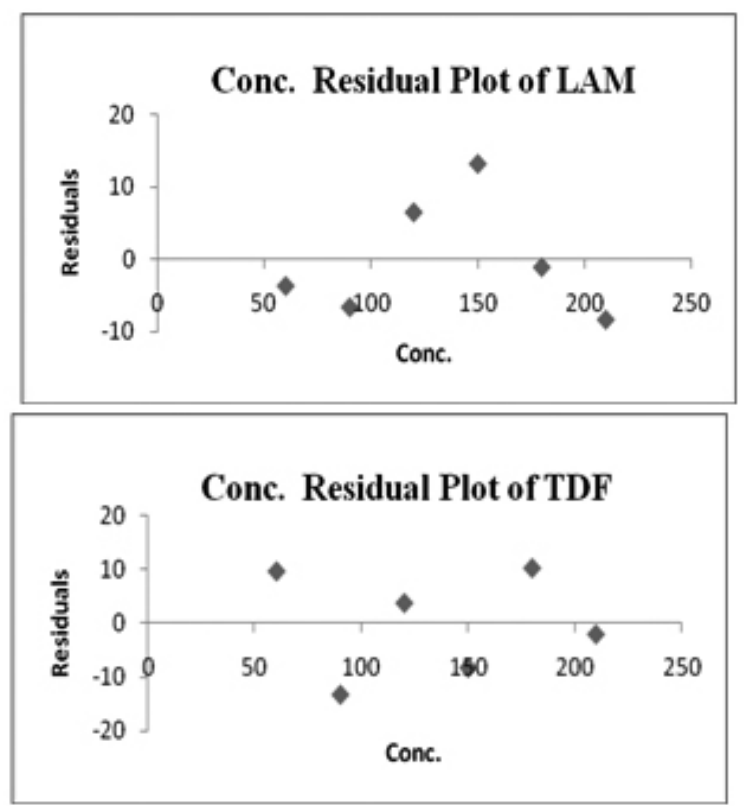

Figure 5. Concentration vs residual plot of LAM and TDF.

Table 1. Linear regression data for calibration curves $(n=6)$

\begin{tabular}{lll|}
\hline Parameters & \multicolumn{1}{c|}{ LAM } & \multicolumn{1}{c|}{ TDF } \\
\hline Linearity range & $60-210$ ng spot $^{-1}$ & $60-210 \mathrm{ng} \mathrm{spot}^{-1}$ \\
Slope \pm Standard error & $16.14 \pm 0.07286$ & $8.694 \pm 0.08604$ \\
Intercept \pm Standard error & $170.9 \pm 10.63$ & $341.4 \pm 12.31$ \\
Confidence limit of slope $^{\mathbf{a}}$ & 15.94 to 16.34 & 8.454 to 8.931 \\
Confidence limit of intercept $^{\text {a }}$ & 142.0 to 200.4 & 307.2 to 376.2 \\
$\mathrm{r}^{2}$ & 0.9999 & 0.9996 \\
Correlation coefficient (r) $^{\text {Sy.X }}{ }^{\mathbf{b}}$ & 1.0000 & 0.9998 \\
P value $^{\mathbf{c}}$ & 9.144 & 10.80 \\
\hline
\end{tabular}

a $95 \%$ Confidence intervals

${ }^{\mathrm{b}}$ Standard deviation of residuals from line

c $\mathrm{P}$ value is $<0.0001$, considered extremely significant.

\section{Precision}

The \% R.S.D. values depicted in Table 2. shows that proposed method provides acceptable intra-day and inter-day variation of LAM and TDF.
The repeatability of sample application and measurement of peak area were expressed in terms of \% R.S.D. and were found to be $0.49,0.63$ and $1.03,1.26$ for LAM and TDF, respectively.

Table 2. Intra-day and inter-day precision of LAM and TDF $(n=6)$.

\begin{tabular}{|c|c|c|c|c|c|c|c|}
\hline \multirow[b]{2}{*}{ Drugs } & \multirow{2}{*}{$\begin{array}{c}\text { Conc. } \\
\left(\text { ng }^{-1}\right. \\
\left.\text { spot }^{-1}\right)\end{array}$} & \multicolumn{3}{|c|}{ Repeatability } & \multicolumn{3}{|c|}{ Intermediate precision } \\
\hline & & $\begin{array}{c}\text { found conc. } \\
\pm \mathrm{SD}\end{array}$ & $\begin{array}{c}\% \\
\text { R.S.D. }\end{array}$ & S.E. & $\begin{array}{c}\text { found conc. } \\
\pm \mathrm{SD}\end{array}$ & $\begin{array}{c}\% \\
\text { R.S.D. }\end{array}$ & S.E. \\
\hline \multirow{3}{*}{ LAM } & 60 & $60.96 \pm 0.36$ & 0.59 & 0.21 & $61.16 \pm 0.21$ & 0.34 & 0.12 \\
\hline & 150 & $150.32 \pm 0.19$ & 0.13 & 0.1 & 150.12 & 0.21 & 0.19 \\
\hline & 210 & 211. & 0.07 & 0.09 & 211.5 & 0. & 0.16 \\
\hline \multirow{3}{*}{ TDF } & 60 & $61.44 \pm 0.21$ & 0.34 & 0.12 & $61.67 \pm 0.37$ & 0.60 & 0.21 \\
\hline & 150 & $149.62 \pm 0.42$ & 0.28 & 0.24 & $149.42 \pm 0.28$ & 0.19 & 0.16 \\
\hline & 210 & $209.92 \pm 0.12$ & 0.06 & 0.07 & $210.09 \pm 0.24$ & 0.11 & 0.14 \\
\hline
\end{tabular}

\section{Robustness}

The standard deviation of the peak areas were calculated for each parameter and the $\%$ R.S.D. was found to be less than $2 \%$. The low values of the \% R.S.D., as shown in Table 3. indicated the robustness of the method.

Table 3. Robustness testing of method $(n=6)$.

\begin{tabular}{|l|l|l|l|l|}
\hline \multirow{2}{*}{ Parameters } & \multicolumn{2}{|l|}{ SD of peak area ${ }^{\text {a }}$} & \multicolumn{2}{l|}{ \%R.S.D. ${ }^{\text {a }}$} \\
\cline { 2 - 5 } & LAM & TDF & LAM & TDF \\
\hline $\begin{array}{l}\text { Mobile phase composition } \\
( \pm 0.1 \mathrm{ml})\end{array}$ & 2.78 & 3.12 & 0.75 & 1.12 \\
\hline $\begin{array}{l}\text { Amount of mobile phase } \\
( \pm 5 \%)\end{array}$ & 1.54 & 2.36 & 0.17 & 0.62 \\
\hline $\begin{array}{l}\text { Time from spotting to } \\
\text { chromatography (+10 min) }\end{array}$ & 2.53 & 2.61 & 0.42 & 0.54 \\
\hline $\begin{array}{l}\text { Time from chromatography } \\
\text { to scanning (+10 min) }\end{array}$ & 1.74 & 2.42 & 0.24 & 0.39 \\
\hline
\end{tabular}

"Average of three concentrations 60, 150, $210 \mathrm{ng} \mathrm{spot}^{-1}$ for LAM and TDF, respectively.

\section{Limit of detection and limit of quantitation}

The signal/noise ratios 3:1 and 10:1 were considered as LOD and LOQ, respectively. The LOD and LOQ were found to be $20,40 \mathrm{ng} \mathrm{spot}^{-1}$ and 30,60 ng spot ${ }^{-1}$ for LAM and TDF, respectively.

\section{Specificity}

The specificity was noticed by the complete separation of LAM and TDF peaks. The peak purity of LAM and TDF was assessed by comparing their respective spectra at the peak start, apex and peak end positions of the spot i.e., $r(S, M)=0.9979$ and $r(M, E)=0.9986$. A good correlation $(r=0.9981)$ was also obtained between the standard and sample spectra of LAM and TDF, respectively.

Accuracy

As shown from the data in Table 4, satisfactory recovery $\%$ in the limit of $98-102 \%$ with small relative standard deviations (\% R.S.D.) obtained at various added concentrations. The results indicate that the method is highly accurate for simultaneous determination of the two drugs.

Table 4. Accuracy studies for the determination of (a) LAM and (b) TDF $(\mathrm{n}=6)$.

\begin{tabular}{|c|c|c|c|c|c|}
\hline $\begin{array}{c}\text { Excess drug } \\
\text { added to the } \\
\text { analyte (\%) }\end{array}$ & $\begin{array}{c}\text { Theoretical } \\
\text { content (ng }_{\left.\text {spot }^{-1}\right)}\end{array}$ & $\begin{array}{c}\text { Measured } \\
\text { conc. } \pm \text { SD }\end{array}$ & $\begin{array}{c}\text { Recovery } \\
(\%)\end{array}$ & \%R.S.D. & S.E. \\
\cline { 1 - 4 } (a) LAM & 90 & $\begin{array}{c}90.84 \pm \\
0.60\end{array}$ & 100.93 & 0.66 & 0.24 \\
\hline 50 & 120 & $\begin{array}{c}119.56 \pm \\
0.32\end{array}$ & 99.63 & 0.26 & 0.13 \\
\hline 100 & 150 & $\begin{array}{c}149.62 \pm \\
0.86\end{array}$ & 99.75 & 0.57 & 0.35 \\
\hline 150 & 90 & $\begin{array}{c}89.54 \pm \\
0.76\end{array}$ & 99.49 & 0.85 & 0.31 \\
\hline (b) TDF & 120 & $\begin{array}{c}119.24 \pm \\
0.54\end{array}$ & 99.37 & 0.45 & 0.22 \\
\hline 50 & 150 & $\begin{array}{c}149.22 \pm \\
0.56\end{array}$ & 99.48 & 0.37 & 0.23 \\
\hline 100 & & & & & \\
\hline
\end{tabular}


Analysis of a marketed pharmaceutical dosage form

Using the proposed chromatographic method, assay of LAM and TDF in their tablets (TAVIN-L, label claim: $300 \mathrm{mg}$ LAM and $300 \mathrm{mg}$ TDF per tablet, B. No. 01A10009, Emcure Pharmaceuticals Ltd.) was carried out. The peaks at $R_{\mathrm{f}} 0.27$ for LAM and $R_{\mathrm{f}} 0.51$ for TDF were observed in the densitogram of the drug samples extracted from tablets. There was no interference from the excipients commonly present in the tablets (Figure 6). Satisfactory results were obtained for both drugs in a good agreement with the label claim. The drug content was found to be $99.82 \% \pm 0.98$ (\%R.S.D. of 0.98 ) and $98.78 \% \pm 1.06$ (\%R.S.D. of 1.07) for LAM and TDF, respectively.

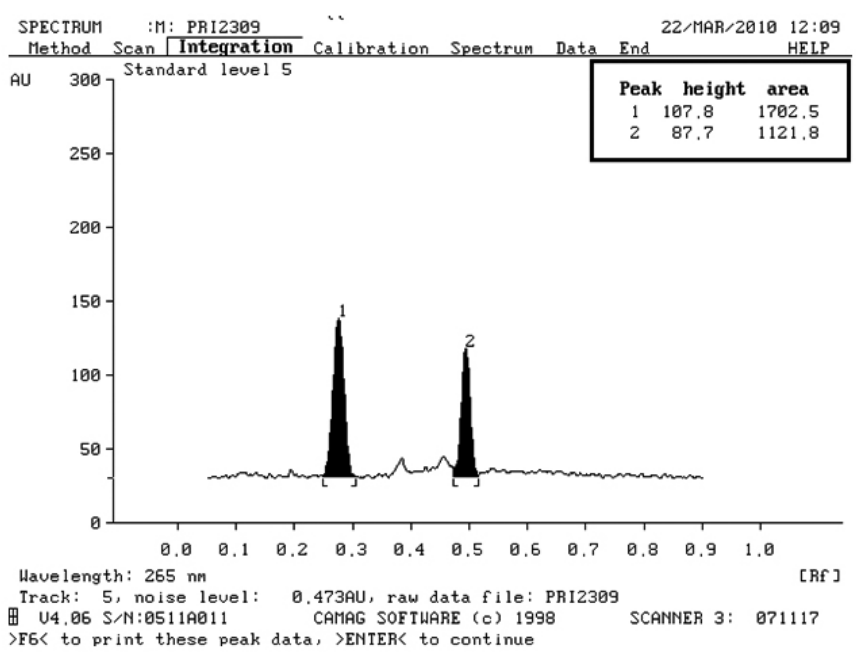

Figure 6. Densitogram of pharmaceutical dosage form containing $120 \mathrm{ng}$ $\operatorname{spot}^{-1}$ of LAM $\left(R_{f} 0.27\right)$ and $120 \mathrm{ng} \mathrm{spot}^{-1}$ of TDF $\left(R_{f} 0.51\right)$.

\section{CONCLUSION}

The developed HPTLC technique is precise, specific, robust and accurate. Statistical analysis proves that the method is suitable for routine analysis of LAM and TDF in pharmaceutical dosage form. The proposed HPTLC method is less expensive, simpler, rapid, and more flexible than LC.

\section{ACKNOWLEDGEMENT}

Authors thank Emcure Pharmaceuticals Ltd., Pune, India for providing gift sample of standards LAM and TDF and Poona College of Pharmacy, Bharati Vidyapeeth Deemed University for providing facilities and encouragement for carrying out this study.

\section{REFERENCES}

1. V. Skalski, C. N. Chang, G. Dutschman, Y. C. Cheng, J. Biol. Chem. 268, 23234-23238, (1993).

2. C. M. Perry, D. Faulds, Drugs 53, 657-680, (1997)

3. W. Y. Gao, R. Agbaria, J. S. Driscoll, H. Mitsuya, J. Biol. Chem. 269, 12633-12638, (1994).

4. The Merck Index, 13th ed., Merck and Co. Inc., Whitehouse Station, NJ, 2001; pp. 1631-32.

5. Martindale. The Complete Drug Reference, 33rd ed., Pharmaceutical Press, London, 2002; pp. 620, 642.

6. T. Chapman, J. McGavin, S. Noble, Drugs 63, 1597-1608, (2003).

7. E. De Clercq, Clin. Microbiol. Rev. 16, 569-596, (2003).

8. S. Shalini, V. P. Shanooja, S. A. Jameel, Basima, K. K. Harilal, H. Rajak, V. Ravichandran, Dig. J. Nanomater. Bios. 4 (2), 357-360, (2009).

9. V. Nagulwar, K. Bhusari, Asian J. Chem. 21 (6), 4689-4693, (2009).

10. N. Erk, Pharmazie 59 (2), 106-111, (2004).

11. S. Choudhury, R. K. Patnaik, T. K. Laha, S. Sen, Asian J. Chem. 20 (7), 5254-5258, (2008).

12. N. Hari Krishnan, V. Gunasekaran, C. Roosewelt, V. K. Meher, K. Kalaivani, V. Ravichandiran, Asian J. Chem. 20 (4), 2551-2556, (2008).

13. Z. M. M. Lavra, P. J. R. Neto, R. M. F. Da Silva, F. P. M. De Medeiros, Quimica Nova 31 (5), 969-974, (2008).
14. A. S. Kumari, K. Prakash, K. E. V. Nagoji, M. E. B. Rao, Asian J. Chem. 19 (4), 2642-2646, (2007).

15. N. Kapoor, S. Khandavilli, R. Panchagnula, J. Pharmaceut. Biomed. 41 (3), 761-765, (2006)

16. S. Anbazhagan, N. Indumathy, P. Shanmugapandiyan, S. K. Sridhar, J. Pharmaceut. Biomed. 39 (3-4), 801-804, (2005).

17. A. R. More, A. J. Vaidya, V. V. Vaidya, R. G. Deshmukh, Asian J. Chem. 19 (7), 5493-5498, (2007).

18. Y. Alnouti, C. A. White, M. G. Bartlett, Biomed. Chromatogr. 18 (9), 641647, (2004).

19. S. A. Ozkan, B. Uslu, J. Liq. Chromatogr. R. T. 25 (9), 1447-1456, (2002).

20. G. Bedse, V. Kumar, S. Singh, J. Pharmaceut. Biomed. 49 (1), 55-63, (2009).

21. L. Elens, S. Veriter, J. C. Yombi, V. Di Fazio, R. Vanbinst, D. Lison, P. Wallemacq, V. Haufroid, J. Chromatogr. B. 877 (20-21), 1805-1814, (2009).

22. G. Habte, A. Hymete, A. M. I. Mohamed, Anal. Lett. 42 (11), 1552-1570, (2009).

23. S. B. Wankhede, K. R. Gupta, M. R. Tajne, S. G. Wadodkar, Asian J. Chem. 18 (4), 2669-2672, (2006).

24. N. Kaul, H. Agrawal, A. R. Paradkar, K. R. Mahadik, Chromatographia 60 (3-4), 213-221, (2004).

25. N. A. Raju, J. V. Rao, K. V. Prakash, K. Mukkanti, K. Srinivasu, Oriental Journal of Chemistry 24 (2), 645-650, (2008).

26. P. B. Kandagal, D. H. Manjunatha, J. Seetharamappa, S. S. Kalanur, Anal. Lett. 41 (4), 561-570, (2008).

27. T. Delahunty, L. Bushman, B. Robbins, C.V. Fletcher, J. Chromatogr. B $877(20-21), 1907-1914,(2009)$

28. N. A. Gomes, V. V. Vaidya, A. Pudage, S. S. Joshi, S. A. Parekh, J. Pharmaceut. Biomed. 48 (3), 918-926, (2008).

29. M. Joshi, A. P. Nikalje, M. Shahed, M. Dehghan, Indian J. Pharm. Sci. 71 (1), 95-97, (2009).

30. ICH Q2 (R1), Validation of analytical procedures: text and methodology. International conference on harmonization, Complementary Guideline on Methodology, 6 November 1996, incorporated in November 2005. 